\title{
Recovery of elbow function in voluntary positioning of the hand following hemiplegia due to stroke
}

\author{
Alan M Wing, Sinclair Lough, Ailie Turton, Carole Fraser, John R Jenner
}

\begin{abstract}
Elbow movement during voluntary positioning of the hand (with the arm supported against gravity) is described in a longitudinal study of five patients recovering from hemiplegia due to stroke. Over a twelve month period, four of the patients improved their speed of movement, three exhibiting slightly better recovery of elbow extension, one of flexion. In some instances co-contraction of the elbow agonist and antagonist (measured just before the onset of movement) decreased with time after stroke. The effects of contrasting movements at the shoulder on elbow movement were also studied. Estimates of recovery were generally similar whether patients kept the shoulder still or made movements that were synergic or counter-synergic to those of the elbow
\end{abstract}

Arm function, lost as a result of hemiparesis due to stroke, often recovers poorly. The frequently cited report of Twitchell ${ }^{1}$ states that recovery proceeds through various stages with flexion of the shoulder and elbow improving before extension. However, this view was based on clinical observations and no attempt at quantification was made. Consequently, it is not known, for example, whether improvements in elbow extension movements proceed at a similar rate to flexion but with a constant lag, or whether extension movements recover at a different, slower rate. There are no quantitative data on how the recovery of the two directions of elbow movement are "locked" together. In this paper we report new data on the recovery of elbow function collected in a longitudinal study of five patients over a period of one year.

\section{Assessing recovery}

Early quantitative approaches to characterising recovery of movement following stroke were based on subjective ratings of the performance of certain manoeuvres. Such studies indicated that the general course of recovery is initially rapid with declining gains after eight to 12 weeks. ${ }^{23}$ The use of test procedures yielding objective performance measures, such as the accuracy or duration of some pre-specified movement (for example, cyclic cranking of a wheel $^{45}$; hand positioning ${ }^{6}$ ) has generally supported this picture. But such tasks require the coordination of several anatomically distinct elements and the performance measures used did not distinguish their relative contributions. In this paper the task chosen involves hand positioning since it provides a clearly-defined, comprehensible goal, but measurement focuses on the kinematics of one joint, the elbow.

Though simple to analyse, isolated movements are not necessarily easy to produce. This point could be particularly relevant when patients with impaired movement are being tested. Thus, Brunnstrom ${ }^{7}$ has suggested that stroke patients should, at least in the early stages, be encouraged to capitalise on synergy patterns to facilitate movement. From this perspective, a task requiring isolated movement at one joint might be expected to provide misleadingly low estimates of ability. It could, however, be argued the other way. If certain combinations of movement over two joints constitute spastic synergy patterns, these might interfere with voluntary movement. This view relates to Bobath's ${ }^{8}$ position, that spastic synergy patterns of movement should be avoided as they result in increases in muscle tone that will inhibit voluntary movement. In this latter view, estimates of performance might be better if such patterns were avoided. The following study thus includes an explicit analysis of the effects of a "context" for elbow movement set by movement at the shoulder. While the task was always defined for the subject in terms of positioning the hand in relation to a visuallyspecified target, the required contribution of the shoulder was varied by changing the hand's starting and target positions.

\section{Representing data on recovery}

Different people recover from stroke at varying rates and to differing degrees, so group average data are likely to be misleading. One approach to this problem of individual differences has been to partition group data into cases exhibiting greater or lesser degrees of recovery. ${ }^{45}$ However, without independent criteria for such a sub-division this post hoc approach appears somewhat arbitrary. In the absence of any principled basis for the description of the time course of recovery, an alternative procedure of reproducing all the individual data points for each subject might be considered appropriate. ${ }^{9}$ The problem with this procedure is that errors of measurement combined with individual variation can result in a confusing picture. In this paper we adopt an approach based on fitting smooth recovery curves to the set of data for each patient. The curves used 
Table 1 Subject details of the five stroke patients. The clinical assessments were those in the case notes corresponding to the time (in days following stroke) of admission to the study

\begin{tabular}{llllll}
\hline & \multicolumn{2}{l}{ Patient } & & & \\
\cline { 2 - 6 } & $A H$ & $R B$ & $M R$ & $D P$ & $J S$ \\
\hline Age (years) & 27 & 57 & 59 & 64 & 75 \\
Sex & $\mathrm{F}$ & $\mathrm{M}$ & $\mathrm{F}$ & $\mathrm{F}$ & $\mathrm{M}$ \\
Hand preference & $\mathrm{R}$ & $\mathrm{L}$ & $\mathrm{R}$ & $\mathrm{R}$ & $\mathrm{R}$ \\
Paresis & $\mathrm{R}$ & $\mathrm{R}$ & $\mathrm{L}$ & $\mathrm{R}$ & $\mathrm{R}$ \\
Admission (days) & 34 & 14 & 21 & 38 & 35 \\
Tone & Reduced & Reduced & Reduced & Reduced & Increased \\
Proprioception & Normal & Normal & Normal & Normal & Reduced \\
\hline
\end{tabular}

were drawn from a family of curves that embodies the idea that recovery from stroke progresses rapidly at first then levels off at some fixed level, or assymptote. What is taken to vary is the level of this assymptote and the rate at which the assymptote is approached. Estimation of these parameters (using regression procedures to fit recovery curves to the observed data) then allows the comparison of individual patients (or experimental conditions).

\section{Methods \\ Subjects \\ Three female and two male hemiparetic patients, aged 27 to 75 years, consented to take part in testing at sessions spaced over a period of approximately one year. The patients were selected from in patients at Addenbrookes Hospital Rehabilitation Unit. All the patients had acute onset of neurological deficit of presumed vascular origin (see tables 1 and 2). Four had a paresis of the right side, which was the dominant side for three of them. (The patient, MR, with weakness of the left side, which was her non-dominant arm, had suffered a right hemisphere stroke some 10 months previously. However, clinically, it was con- sidered that she had recovered full use of her dominant, right side at the time of admission to this study.) Testing normally only involved the paretic arm. However, performance of the other arm was assessed on at least one occasion around 50 weeks after stroke (with the excep- tion of DP where the interval following stroke was 23 weeks). \\ A sixth subject without known neurological deficit also took part in the study. She was a 67 year old female hospital voluntary worker whose results served as an indication of normal performance. Testing involved her preferred, right side throughout.}

Table 2 Functional movement testing. Time (in weeks following stroke) taken by patients to attain normal rating on personal care activities of daily living, ${ }^{\prime \prime} 50^{\circ}{ }^{\circ}$ of normal rating on measures of Upper Limb and Lower Limb activity" and fine motor skill. The last test, adapted from Annett et al, ${ }^{2}$ involves using the hand to transfer a set of 10- mm wood dowel pegs between two rows of $11 \mathrm{-mm}$ diameter holes at 205- $\mathrm{mm}$ centres

\begin{tabular}{|c|c|c|c|c|c|}
\hline \multirow[b]{2}{*}{ Test } & \multicolumn{5}{|c|}{ Patient } \\
\hline & $A H$ & $R B$ & $M R$ & $D P$ & $J S$ \\
\hline $\begin{array}{l}\text { ADL } \\
\text { Upper Limb } \\
\text { Lower Limb } \\
\text { Peg transfer }\end{array}$ & $\begin{array}{l}13 \\
17 \\
13 \\
31\end{array}$ & $\begin{array}{r}2 \\
3 \\
2 \\
17\end{array}$ & $\begin{array}{r}8 \\
14 \\
4 \\
>54_{+}^{+}\end{array}$ & $\begin{array}{l}37 \\
46 \\
21 \\
\text { NA }\end{array}$ & $\begin{array}{c}>54^{\star} \\
>54^{\dagger} \\
18 \\
\text { NA }\end{array}$ \\
\hline
\end{tabular}

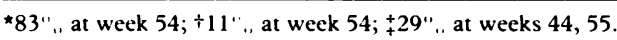

\section{Apparatus}

Subjects were tested sitting in a wheelchair. For an assessment relatively early after stroke, the wheelchair was modified to support and allow free movements of both forearms in a horizontal plane just below shoulder level. ${ }^{13}$ Each forearm was supinated to allow the hand to rest around a steep-sided, vertically-oriented cone. In this situation arm movements were restricted to two degrees of freedom; flexion and extension of the elbow and horizontal (forward) flexion and horizontal (backward) extension of the shoulder. ${ }^{1}$

During testing, the wheelchair was placed with the arm supports underneath a clear perspex work surface positioned at chin height. The tops of the cones were just below this perspex surface. They were clearly visible in relation to pairs of $30 \mathrm{~mm}$ discs that were placed on the top surface of the perspex. These discs defined start and target positions for hand positioning movements. During the movements shoulder and joint angle changes in the horizontal plane were registered using singleaxis potentiometers that were kept in position over the joints with a lightweight, tubular "exo-skeleton". The "exo-skeleton", which was held in place on the arm with velcro straps, was equipped with sliding joints that removed small translational movements arising from any slight mismatch of elbow or shoulder joints and the axes of the potentiometers.

To assess the relation between agonist and antagonist activity, electromyography was carried out both early and late in recovery. Pairs of silver-plated, $19 \mathrm{~mm}$ diameter surface electrodes were positioned 50mms apart over the biceps and triceps. A ground plate was attached at the elbow. The EMG signal was led to a battery-operated amplifier (Bio-logic Devices Myosone 404) operating with a 0.01 to $0.5 \mathrm{mV}$ input range and a Butterworth filter of bandwidth $100-500 \mathrm{~Hz}$ and $18 \mathrm{~dB} /$ octave rolloff.

Potentiometer voltages, together with EMG signals (passed through an isolation stage) were fed to a FM instrumentation tape recorder (Racal Store 4D) running at a tape speed that limited the signal bandwidth to $0-625 \mathrm{~Hz}$. Following each session the analog recordings were digitised at $250 \mathrm{~Hz}$. After rectification, flexor and extensor EMG values were scaled by levels observed during maximum voluntary contraction (MVC). These levels were estimated from two sets of three 3 second trials during which patients exerted maximal elbow torque (either flexion or extension) against resistance offered by the experimenter. Average EMG levels were determined for a 0.5 second period taken midway through each trial. The trials were run at the beginning of the session and were followed by a number of cycles of passive flexion and extension before carrying out the experimental task.

Task

After the subject's arm had been moved passively to the start position, illumination of a light emitting diode accompanied by the verbal command "Ready" signalled the beginning of a 
Figure 1 Position of start and target markers for right arm isolated elbow flexion $(F I, 12)$ and extension (FE, 21); synergic shoulder movement with elbow flexion ( FS, 34) and extension (ES, 43); movement with elbow flexion $(F C, 56)$ and extension $(E C, 65)$. counter-synergic shoulder

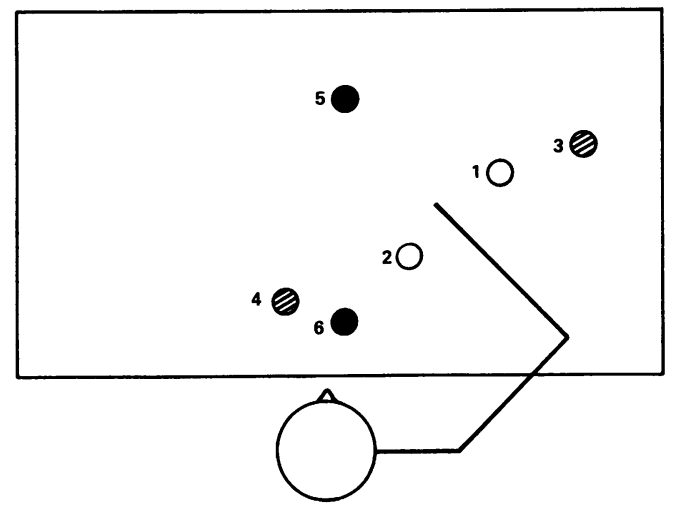

trial. Following a variable delay of one to two seconds, the light emitting diode was turned off which served as a signal to the subject to move the hand quickly and accurately to a position under the target disc. The end of each trial was identified by the experimenter as the time when the patient settled at a position near or under the target. Early after stroke, patients were sometimes unable to attain the target. In such cases trials were terminated after five seconds or when the experimenter judged the patient was no longer attempting to move.

The positions of start and target discs were chosen to yield flexion and extension movements of the elbow of approximately $20^{\circ}$ on either side of mid-extension (see fig 1 ). Flexion (F) and extension (E) were combined factorially with three conditions of shoulder movement. In the isolated condition (1), shoulder movement was inappropriate and only elbow movement was required to achieve the position of the target disc. In the synergy condition (S), movement of the shoulder in the same direction as that of the elbow was required. This condition associated, for example, elbow flexion with shoulder horizontal flexion

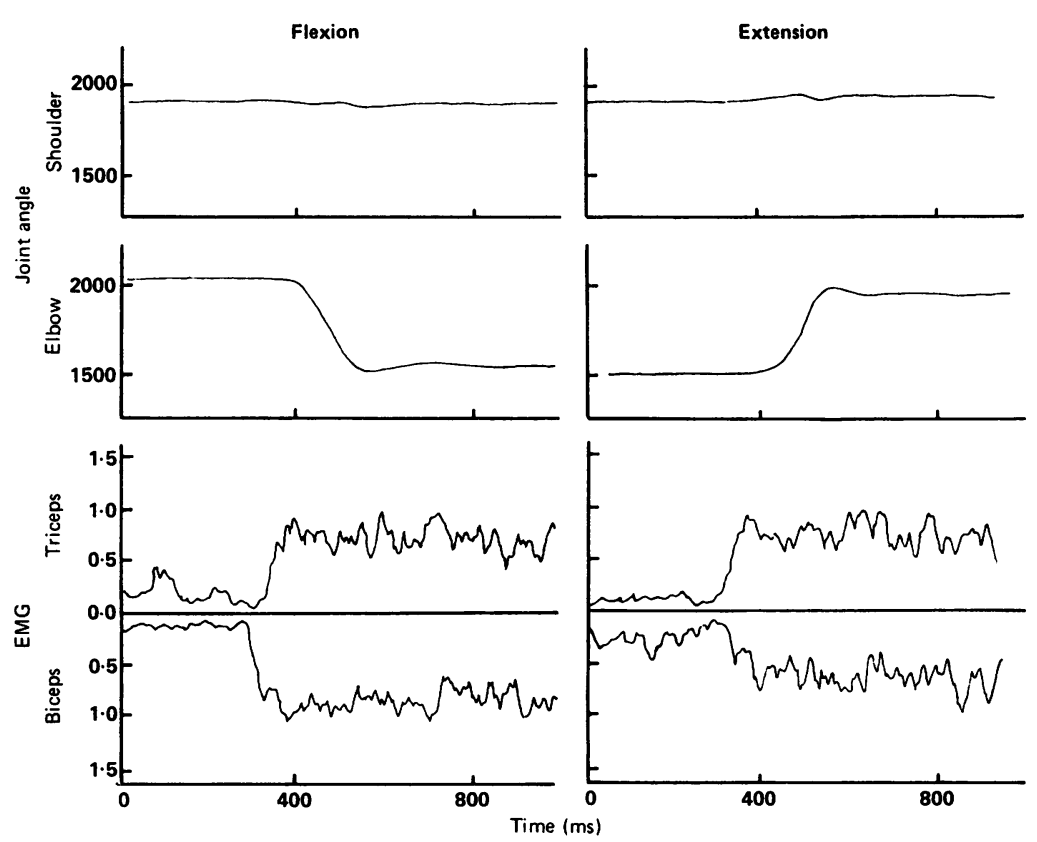

Figure 2 Illustrative recordings from trials involving isolated flexion (FI) and extension (EI) for the control subject PW. A change in elbow angle of approximately 40 degrees is accompanied by minimal change of shoulder angle. EMG (expressed as a proportion of MVC) is also shown for biceps below the line, triceps above to "match" the directions of the elbow angular movement trajectory. and required the greatest spacing of the start and target discs. The counter-synergy condition $(\mathrm{C})$ required movement of the shoulder in the opposite direction to that of the elbow. In this condition elbow flexion, for example, was associated with shoulder horizontal extension (resulting in movement of the hand in the saggital plane toward the body). Trials with the same positions for the start and target numbers were run in blocks of five.

Sample recordings (from week 31) are shown for the control subject $P W$ in fig 2. A rapid change in elbow angle (with little change in shoulder angle) is accompanied by sustained activity of the agonist and (with a slight delay in onset) of the antagonist. Co-contraction of agonist and antagonist after completion of the movement was evident in all this subject's data and probably reflects the low friction afforded by the arm support.

\section{Kinematics}

In positioning the hand it is normally observed that an initial, fast, distance-covering component is followed by one or more corrections that serve to home the hand onto the target. ${ }^{14-16}$ The first peak in velocity is usually the greatest and occurs early, usually 100 to $200 \mathrm{~ms}$ after movement onset. This peak velocity may be taken as providing a measure of open-loop driving of the motor system unaffected by visual feedback which can only be effective after several hundred $\mathrm{ms} .{ }^{17}$ Peak velocity has proved a useful and tractable measure when working with patients with motor disorders. ${ }^{13}{ }^{18-20}$ In this study, the decision was taken to characterise elbow movement in terms of peak angular velocity. Data for each trial were scanned to determine movement onset (defined by a change in elbow angle of more than $0.3 \mathrm{deg}$ in a 12-ms "window") and maximum excursion of the elbow. Elbow velocity was then computed by step-wise successive differences in angle and the maximum velocity and the time at which it occurred was determined.

As an index of the "regularity" of movement, the change in elbow angle up to peak velocity was evaluated as a proportion of the maximum angular excursion of the elbow. In the patients the peak angular velocity of the elbow was attained at around 40 to $50 \%$ of full excursion. The value for the control subject was $50 \%$ which agrees with previously published phase plane plots of normal hand positioning movements. ${ }^{16}$ No consistent changes with recovery were noted in this measure. However, it was observed that the control subject exhibited considerably greater trial-by-trial consistency.

The (signed) angular change of the elbow at peak velocity relative to the change in shoulder angle at this time provides an indication of how subjects' movements conformed to the task requirements. The values for all subjects were approximately zero in the isolated elbow condition, greater than zero in the synergy condition and less than zero in the counter-synergy. In the case of the latter two conditions, the control subject (who, again, exhibited relatively little trial-to-trial variation) exhibited values of plus 
and minus one. This indicates, in absolute terms, a correspondence of the angular changes at the shoulder and elbow consistent with previous research on shoulder-elbow coordination. ${ }^{21}$ Apart from JS, whose data were very variable, the patients produced changes in shoulder angle that were slightly greater than those at the elbow for the synergy conditions but that were slightly smaller in the countersynergy case.

\section{Results}

Recovery curve description

To define recovery curves for each patient/ experimental condition combination, the mean peak velocity for each session was plotted as a function of number of weeks after stroke (see figs 3 and 4). A quantitative description of each patient's recovery in each condition was obtained in terms of two statistics, the final recovery level and the initial rate of recovery.
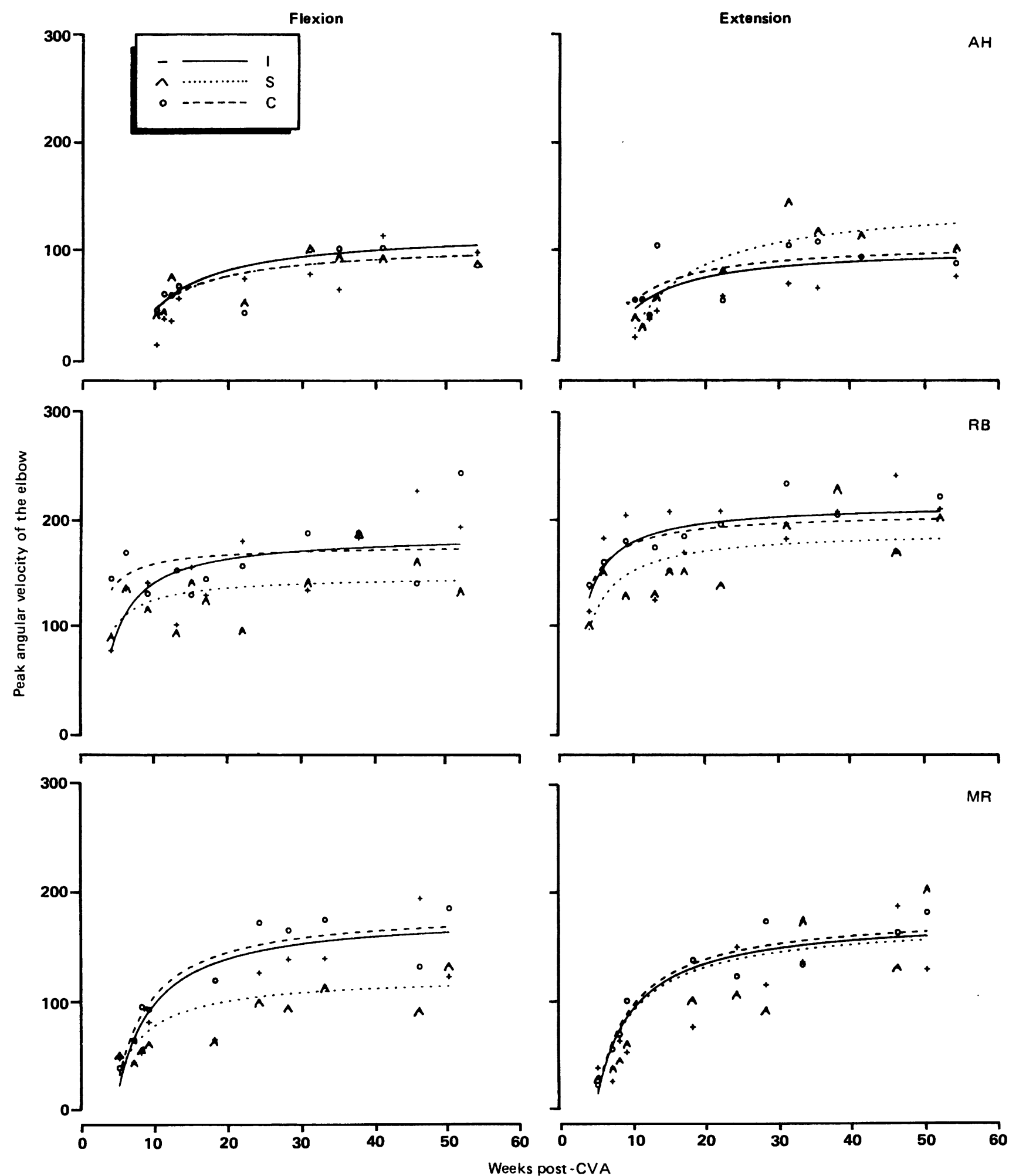

Figure 3 Peak elbow angular velocities of flexion (left) and extension (right) in isolated (I), shoulder synergy (S) and shoulder counter-synergy (C) conditions for patients $A H$ (top), $R B$ (middle) and $M R$ (bottom). 
These statistics correspond respectively to the constants $a$ and $b$ in the reciprocal time function: $V \max =a-b / N$, where $V \max$ is the average maximum elbow angular velocity at $N$ weeks after stroke, $a$ is a fixed assymptote and $b$ is the tangential slope of the recovery function at week 1 . The constants were estimated using standard procedures for least-squares, linear regression after first transforming the raw data. ${ }^{2}$ In these terms, the data for a patient showing no recovery would be fit by a function with an estimate of the initial recovery rate parameter, $b$, lying near zero and a low value of the final recovery level, a.

Inspection of the control subject's data set indicated the presence of changes in perfor- mance from the first to the second session. In the first session some of the observed peak velocities fell considerably below the values in the following weeks. The decision was therefore taken to carry out the linear regressions for all subjects after exclusion of the data from the first session. ${ }^{3}$

Inspection of the fitted recovery functions in figs 3 and 4 indicates a range of final recovery levels reached at varying rates. The curves generally levelled off by 20 weeks after stroke. The exact values of the recovery function parameters are provided in tables 3 and 4 . Table 3 shows that the final recovery levels attained by the patients were generally below the overall mean peak angular velocity of the
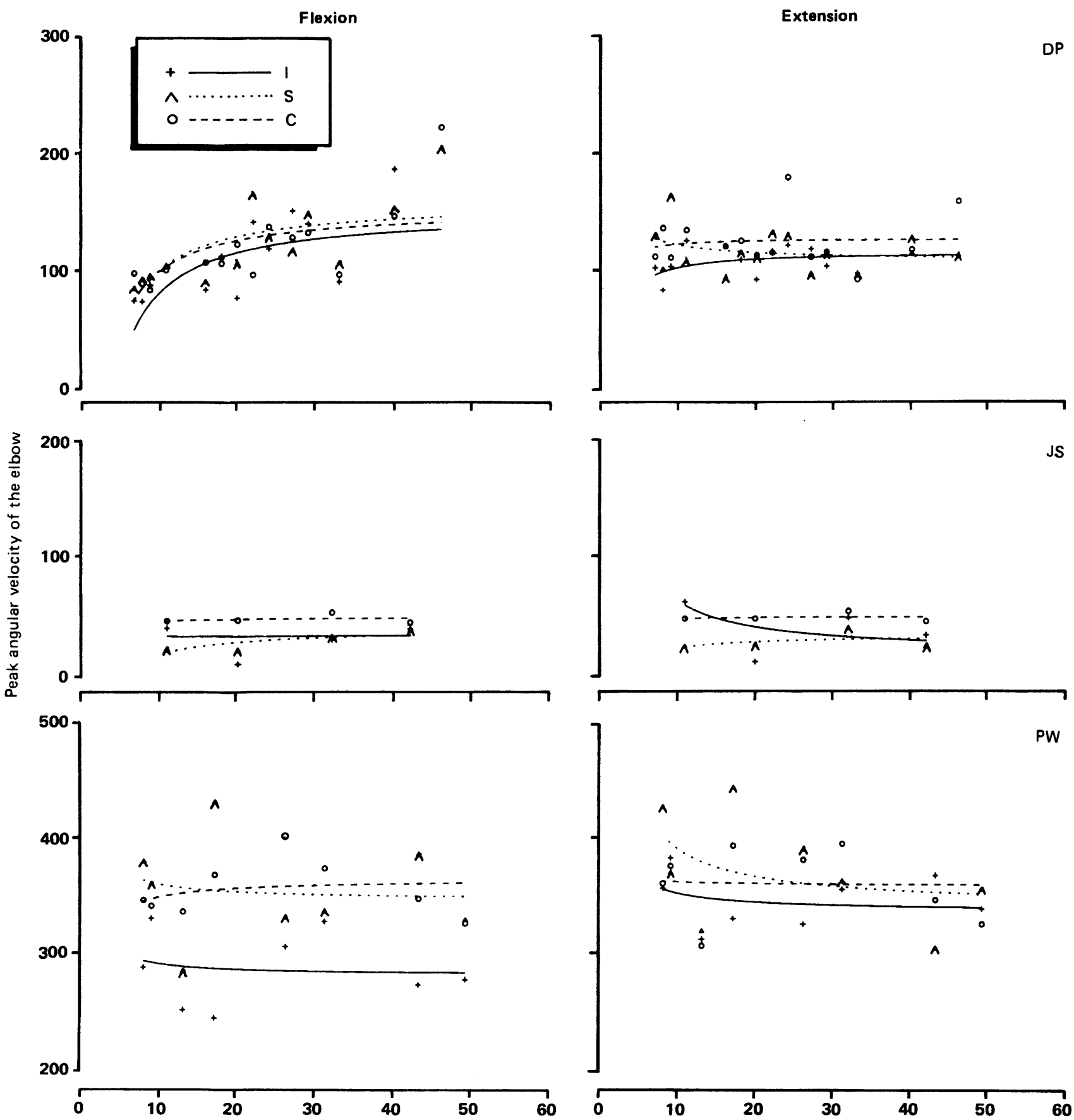

Weeks post-CVA

Figure 4 Peak elbow angular velocities for patients DP (top), JS (middle) and the control subject PW (bottom). 
Table 3 Assymptotic values ( $\mathrm{deg} / \mathrm{s}$ ) of peak angular velocity of the elbow during flexion or extension movements that were either executed in isolation $(I)$, in combination with synergic $(S)$, or counter-synergic $(C)$ movement of the shoulder. Single session estimates of the peak angular velocity of the ipsilateral elbow (averaged over conditions ) for patients $A H$ through $J S$ were $132,254,142,170$ and $242 \mathrm{deg} / \mathrm{s}$ respectively

\begin{tabular}{|c|c|c|c|c|c|c|c|}
\hline \multirow{3}{*}{\multicolumn{2}{|c|}{ Condition }} & \multicolumn{6}{|c|}{ Subject } \\
\hline & & \multicolumn{5}{|c|}{ Patient } & \multirow{2}{*}{$\frac{\text { Control }}{P W}$} \\
\hline & & $A H$ & $R B$ & $M R$ & $D P$ & $J S$ & \\
\hline Flex & $\begin{array}{l}I \\
S \\
\text { C }\end{array}$ & $\begin{array}{l}116 \\
104 \\
104\end{array}$ & $\begin{array}{l}186 \\
148 \\
176\end{array}$ & $\begin{array}{l}180 \\
124 \\
184\end{array}$ & $\begin{array}{l}150 \\
158 \\
154\end{array}$ & $\begin{array}{l}32 \\
36 \\
48\end{array}$ & $\begin{array}{l}280 \\
346 \\
364\end{array}$ \\
\hline Ext & $\begin{array}{l}\text { I } \\
\text { S }\end{array}$ & $\begin{array}{l}104 \\
146 \\
108\end{array}$ & $\begin{array}{l}214 \\
190 \\
206\end{array}$ & $\begin{array}{l}174 \\
170 \\
178\end{array}$ & $\begin{array}{l}118 \\
110 \\
130\end{array}$ & $\begin{array}{l}16 \\
30 \\
48\end{array}$ & $\begin{array}{l}338 \\
342 \\
360\end{array}$ \\
\hline \multicolumn{2}{|c|}{ Pooled SE } & 4 & 4 & 4 & 6 & 6 & 10 \\
\hline
\end{tabular}

Table 4 Recovery slopes ( $\mathrm{deg} / \mathrm{s} /$ week) of peak angular velocity of the elbow during flexion or extension movements executed in isolation (I), in combination with synergic $(S)$, or counter-synergic ( $C$ ) movement of the shoulder

\begin{tabular}{|c|c|c|c|c|}
\hline \multirow{3}{*}{\multicolumn{2}{|c|}{ Condition }} & \multicolumn{3}{|c|}{ Subject } \\
\hline & & \multicolumn{2}{|l|}{ Patient } & \multirow{2}{*}{$\frac{\text { Control }}{P W}$} \\
\hline & & $A H$ & $D P$ & \\
\hline Flex & & $\begin{array}{l}694 \\
582 \\
569\end{array}$ & $\begin{array}{l}704 \\
586 \\
542\end{array}$ & $\begin{array}{r}-104 \\
-136 \\
142\end{array}$ \\
\hline Ext & & $\begin{array}{r}574 \\
1188 \\
542\end{array}$ & $\begin{array}{r}146 \\
-124 \\
60\end{array}$ & $\begin{array}{r}-146 \\
-488 \\
-24\end{array}$ \\
\hline \multicolumn{2}{|c|}{ Pooled SE } & 56 & 72 & 140 \\
\hline
\end{tabular}

ipsilateral elbow assessed late after stroke. (An exception was MR; this suggests a persisting right-sided paresis due to this patient's earlier stroke). The patients' ipsilateral peak elbow angular velocities all fell below those for the control subject PW, consistent with the suggestion of ipsilateral motor impairment following unilateral cerebral infarction. ${ }^{22}$ The slope estimates for PW may be seen to be small, even

Figure 5 Individual patient recovery curve slopes and assymptotes as a function of elbow movement direction.

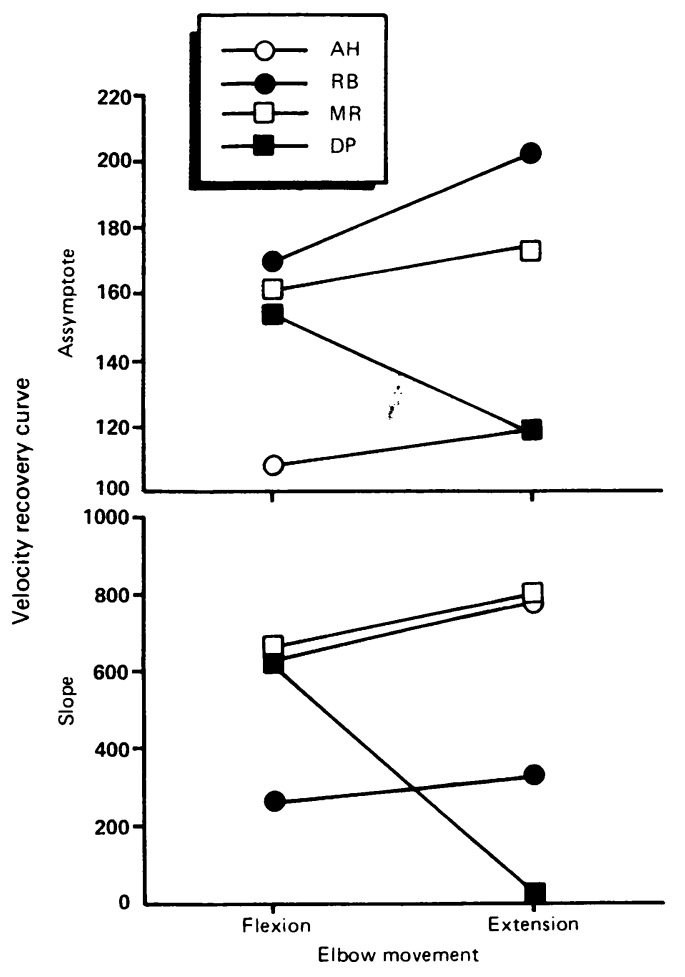

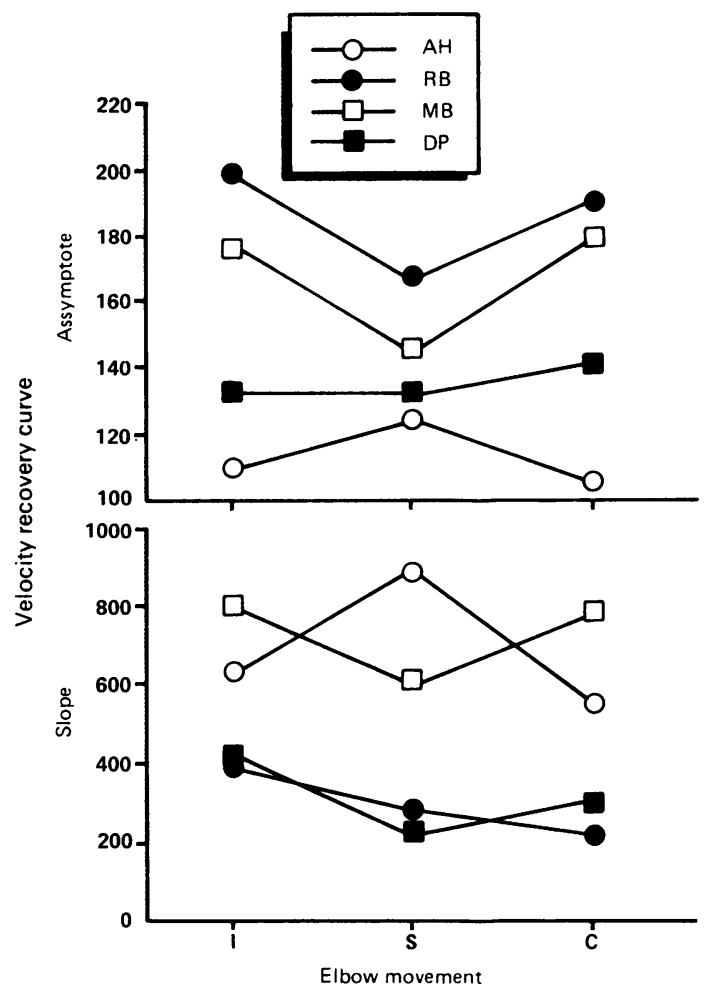

Figure 6 Individual patient recovery curve slopes and assymptotes as a function of shoulder movement.

slightly negative indicating the absence of practice effects. Consistently low values of both slope and intercept may be seen in the case of the patient JS.

Among the four patients exhibiting appreciable recovery, there were differences between flexion and extension recovery; three patients obtained higher values for extension, while DP exhibited higher values in flexion (see fig 5). There were also differences in the recovery curve parameters as a function of shoulder movement (see fig 6) but, in this case, DP did not stand out as appreciably different. In summary, recovery estimates for isolated elbow movement are no lower than for concurrent movement of the shoulder. If anything, in terms of slope, isolated movements tend to be better.

Further support for similarity of the recovery of the two elbow movement directions comes from an analysis of the discrepancy between the observed data and the fitted recovery curves for these four patients. For the most part, moderately large, positive correlations were observed as may be seen in table 5 . The variation of the residuals for flexion and extension is "locked" together. Interestingly, this is less true in the case of the patient DP, whose recovery functions for flexion and extension were least similar. A notably low, indeed negative, correlation was also obtained for MR in the counter-synergy condition.

\section{Electromyography}

Four of the five patients showed recovery. We then examined whether, in these patients, the EMG data indicated a reduction in centrally commanded co-contraction (which would contribute to improved performance over the weeks). An index of co-contraction over a 100 
Table 5 Correlations (computed on the residuals about best-fit regression lines) between peak elbow angular velocity for flexion and extension in isolated (I), synergic $(S)$ and counter-synergic (C) conditions

\begin{tabular}{|c|c|c|c|c|}
\hline \multirow[b]{2}{*}{ Condition } & \multicolumn{4}{|c|}{ Patient } \\
\hline & $A H$ & $R B$ & $M R$ & $D P$ \\
\hline $\begin{array}{l}I \\
S \\
C\end{array}$ & $\begin{array}{l}0.66 \\
0.48 \\
0.67\end{array}$ & $\begin{array}{l}0.87 \\
0.78 \\
0.71\end{array}$ & $\begin{array}{r}0.74 \\
0.68 \\
-0.15\end{array}$ & $\begin{array}{l}0.33 \\
0.41 \\
0.59\end{array}$ \\
\hline
\end{tabular}

Table 6 Means over five trials of pre-movement co-contraction ratios (biceps/triceps) for flexion and extension, early (left columns) and later (right columns) in recovery

\begin{tabular}{|c|c|c|c|c|c|c|c|c|c|c|}
\hline \multirow[b]{3}{*}{ Condition } & \multicolumn{10}{|c|}{ Subject } \\
\hline & \multicolumn{8}{|c|}{ Patient } & \multirow{2}{*}{\multicolumn{2}{|c|}{$\frac{\text { Control }}{P W}$}} \\
\hline & $A H$ & & $R B$ & & $M R$ & & $D P$ & & & \\
\hline $\begin{array}{l}\text { Flex } \\
\text { Ext }\end{array}$ & $\begin{array}{l}0.4 \\
0.7\end{array}$ & $\begin{array}{l}1.4 \\
0.6\end{array}$ & $\begin{array}{l}3.8 \\
0.3\end{array}$ & $\begin{array}{l}3 \cdot 7 \\
0.4\end{array}$ & $\begin{array}{l}0.8 \\
0.3\end{array}$ & $\begin{array}{l}1.9 \\
1.5\end{array}$ & $\begin{array}{l}2 \cdot 6 \\
2 \cdot 1\end{array}$ & $\begin{array}{l}1.9 \\
0.5\end{array}$ & $\begin{array}{l}1.3 \\
0.8\end{array}$ & $\begin{array}{l}1.4 \\
0.8\end{array}$ \\
\hline
\end{tabular}

ms period starting $300 \mathrm{~ms}$ before movement onset was defined by the average flexor EMG (relative to MVC) divided by the average extensor EMG (relative to MVC). The results (based on averages of the ratios computed for each of five trials early and later in recovery) are shown in table 6. Estimates for the control subject, PW, were stable over both trials and sessions with values above 1.0 for flexion and below 1.0 for extension, as would be expected Estimates of the co-contraction ratios for the patients also generally fell within a sensible range. In four cases (flexion-AH, MR, DP extension-DP) the estimates moved closer to those of the control subject. In three cases (flexion-RB; extension-AH, RB) there was virtually no change. And, in one case (extension-MR) the value of the index changed inappropriately. However, on balance, recovery was associated with a decrease in premovement co-contraction which may therefore be taken as a factor contributing to the improvement in movement kinematics.

\section{Discussion}

Positioning of the hand in space is an ability of fundamental importance. A common view ${ }^{23}$ of the underlying nature of control is that, with sufficient time before movement, visual information concerning target location combined with proprioceptive (and perhaps visual) information about the initial position of the hand allows advance specification of a motor programme for the shoulder and elbow musculature. On execution, this programme results in a rapid, open-loop, ballistic approach of the hand into the neighbourhood of the target. Visually-based corrections may then be used to remove any mismatch in position. We take the peak velocity of movement in the distancecovering, ballistic phase, to be an indication of the functional efficacy of the motor system. Of the five patients evaluated in the present study, four exhibited improvement in peak angular velocity of the elbow. The range of estimates of their assymptotic performance levels placed them around $50 \%$ of the normal control subject's performance and at about $85 \%$ with respect to the performance of the arm ipsilateral to the lesion. A wide range of recovery rates was observed. The standard error of these estimates was such that most differences would be statistically reliable. Thus, from a practical view, the technique of fitting recovery curves may be considered satisfactory.

A number of complementary tasks, all formulated in terms of moving the hand to a clearly-defined visual target position, were investigated. These tasks varied the direction of elbow movement (flexion/extension) and the nature of concurrent activity required of the shoulder (flex/stabilise/extend). How do the data bear on the question of whether recovery differs for elbow flexion and extension? Among the patients exhibiting recovery, the biggest contrast between flexion and extension occurred with DP for whom flexion improved more than extension. RB also showed a flexion/ extension contrast, but it was in the other direction so that extension was better than flexion. With broadly similar functions for flexion and extension in the other two patients the conclusion is therefore that there is no evidence of consistently better or faster recovery in flexion as opposed to extension. This conclusion was also supported by the fact that the residuals around the fitted recovery curves were generally positively correlated over flexion and extension. The overall conclusion is therefore against the suggestion ${ }^{1}$ that recovery of flexion precedes extension.

Why did our results not support the latter view, which is widely accepted? Clinically, measures of resisted near-isometric strength are often used to assess voluntary movement. Could this procedural difference be important? A recent analysis of isometric strength capability of stroke patients (taken as just one point on their recovery curve) showed that elbow flexors are relatively more weakened than the extensors. ${ }^{24}$ This might give a greater margin for improvement and hence make elbow flexion recovery more apparent to the clinician. Another point of difference between our testing and the clinical situation is our use of an arm support. In clinical testing the effects of gravity that result in tonic activation of the "anti-gravity" flexor muscles may be misinterpreted as better performance.

Would an alternative performance measure have yielded recovery curves that differed systematically across movement conditions? We believe that the answer to this question is no. Elbow angle is a simple, unambiguous measure and, given arm support, it is one that can be measured early after stroke. Peak velocity is an unambiguous kinematic feature, easy to compute and identify. But other behavioural measures would certainly be worth examining. Oru candidate might be acceleration or its derivative, jerk. ${ }^{25}$ The latter bears a close relation to the number of submovements, a measure that has previously been proved useful. ${ }^{1326}$ It might be argued that our characterisation of the form of recovery was inaccurate and so insensitive to differences related to the movement conditions. Obviously the family of recovery curves that we used is not 
the only possible description that would capture the basic observation of declining gains with passage of time. However, the present study was set up with the aim of taking just a first step with a limited number of subjects and we leave the task of establishing which function fits best as an exercise for future research.

It is interesting to ask what is the basis of the recovery that we observed? In the case of knee joint movements, it has been suggested that the origin of slowed movement in hemiplegia is inappropriate co-contraction at the onset of movement. ${ }^{27}$ Our quantitative analysis of EMG levels before movement in the isolated flexion and extension conditions provided partial support for this interpretation of recovery of elbow movement. In several cases the patients converged on a balance of agonist and antagonist activity that was exhibited by the control subject and that would favour rapid initiation of movement. However, there were certainly exceptions to this and these could have arisen from our definition of co-contraction. In repeated testing it is usually considered advisable that EMG be expressed in relative terms to compensate for variations in electrode placement, resistance etc. In this study EMG values were therefore scaled according to the signal associated with maximal voluntary contraction. If, in recovery, there is a dissociation between activation of paretic muscle in maximal isometric contraction and in low-level isotonic contraction, this would confuse the interpretation of changes in our scaled index of co-contraction.

Hypersensitivity of stretch reflexes in hemiplegia is another possible basis for the impairment of voluntary movement. ${ }^{29}$ If stretch of the antagonist induced by the movement results in activation of the antagonist, the movement will be impeded. Visual inspection of our own data did not reveal clear movement-related, phasic responses in the antagonist. While a quantitative evaluation of both tonic and phasic antagonist EMG related to movement velocity would seem appropriate, ${ }^{30}$ it is worth noting Sahrman and Norton's ${ }^{31}$ analysis of cyclic flexion/extension movements of the elbow. Although movement time correlated with clinical ratings of spasticity, these authors commented that the form of the EMG patterning did not support the hypothesis of hyperexcitable stretch reflexes. They found no evidence of exaggerated antagonist activity in phase with movement.

In this paper, the tasks varied not only the required direction of elbow movement but also the nature of concurrent activity required of the shoulder (flex/stabilise/extend). It is interesting to consider the findings here in terms of possible implications for rehabilitation. ${ }^{32}$ In the introduction, the positions of Brunnstrom $^{7}$ and Bobath ${ }^{8}$ were outlined and it was suggested that these might be taken to suggest that elbow movement would be dependent on the "context" of the movement occurring at the shoulder. Our results, albeit it from a small patient group working under special conditions, indicate that this is not so. Whether movement involved synergic, countersynergic or stabilising action of the shoulder, there were no clear, systematic differences in recovery of peak angular velocity of the elbow. If confirmed by further research such a group result might be taken to suggest that patient assessment (if not the design of treatment) need not take account of synergy patterns of movement. However, there were reliable differences in recovery rates and final recovery levels between patients as a function of movement condition. This indicates that it may, after all, be important to treat each patient separately in selecting the most appropriate movement conditions for the design and evaluation of therapy after stroke.

1 Twitchell TE. The restoration of motor function following hemiplegia in man. Brain 1951;74:443-80.

2 Fugl-Meyer AR, Jaasko L, Leyman I, Olsson S, Steglind S. The post-stroke hemiplegic patient. Scand J Rehab Med 1975;7:13-31.

3 Newman $M$. The process of recovery after hemiplegia. Stroke 1972;3:702-10.

4 DeSouza LH, Langton Hewer R, Miller S. Assessment of arm control in hemiplegic stroke patients 1 . Arm function arm control in hemiplegic stroke patien.

5 DeSouza LH, Langton Hewer R, Miller S. Assessment of arm control in hemiplegic stroke patients 2 . Comparison of arm function tests and pursuit tracking in relation to clinical recovery. Inter Rehab Med 1980b;2:10-6.

6 Turton A, Fraser C. The use of a simple aiming task to measure recovery following stroke. Physiotherapy Practice 1987;3:117-25.

7 Brunnstrom S. Movement Therapy in Hemiplegia. London: Harper and Row, 1970.

8 Bobath B. Adult Hemiplegia Evaluation and Treatment. Second Ed. London: Heinneman, 1978.

9 Heller A, Wade DT, Wood VA, Sunderland A, Langton Hewer $R$, Ward E. Arm function after stroke: measurement and recovery over the first three months. measurement and recovery over the first three
$J$ Neurol Neurosurg Psychiatry 1987;50:714-9.

10 Ashburn A. A physical assessment for stroke patients. Physiotherapy 1982;68:109-13.

11 Whiting F, Lincoln N. An ADL assessment for stroke patients. British J Occ Therapy 1980;43:44-5.

12 Annett M, Hudson PTW, Turner A. The reliability of differences between the hands in motor skill. Neuropsychol 1974;12:527-31.

13 Lough S, Wing AM, Fraser CM, Jenner J. Measurement of recovery of arm function following stroke: a preliminary report. Human Movement Science 1984;3:247-56.

14 Crossman ERFW, Goodeve PJ. Feedback control of handmovement and Fitts' Law. Paper presented at the meeting of the Experimental Psychology Society. Oxford, July 1963. J Exp Psychol 1983;35A:251-78.

15 Langolf GD, Chaffin DB, Foulke JA. An investigation of Fitts' Law using a wide range of movement amplitudes. $J$ Motor Behavior 1976;8:113-28.

16 Jagacinski RJ, Repperger DW, Moran MS, Ward SL, Glass $B$. Fitts' Law and the microstructure of rapid discrete movements. J Exper Psychol (Human Perception and Performance) 1980;6:309-20.

7 Sheridan MR. Planning and controlling simple movements. In: Smyth MM, Wing AM, eds. The Psychology of Human Movement. London: Academic, 1984.

18 Wing AM, Miller E. Peak velocity timing invariance. Psychol Res 1984;46:121-7.

19 Lough S. Visuo-motor control following stroke. Unpublished PhD Thesis, Edinburgh University 1984

20 Lough S. Visual control of arm movement in the stroke patient. Inter Rehab Med 1987;10(Suppl):113-9.

21 Lacquaniti F, Soechting JF. Coordination of arm and wrist motion during a reaching task. J Neurosc $1982 ; 2: 399-408$.

22 Jones RD, Donaldson M, Parkin PJ. Impairment and recovery of ipsilateral sensory-motor function following unilateral cerebral infarction. Brain 1989;112:112-32.

23 Keele SW. Behavioral analysis of movement. In: Brooks VB, ed. Handbook of Physiology, Section 1, The Nervous System, Vol II, Motor Control, Pt 2. Bethesda, MD: Am Physiol Soc, 1981

24 Colebatch JG, Gandevia SC, Spira PJ. Voluntary muscle strength in hemiparesis: distribution of weakness at the elbow. J Neurol Neurosurg Psychiatry 1986;49:1019-24.

25 Wann J. The Control of Fine Motor Trajectories. Unpublished PhD Thesis. Cambridge University, 1988.

26 Lee DN, Lough F, Lough S. Activating the perceptuomotor system in hemiparesis. $J$ Physiol 1984;349:28.

27 McLellan DL. Co-contraction and stretch reflexes in spasticity during treatment with baclofen. J Neurol Neurosurg ticity during treatment with
Psychiatry 1977;40:30-8.

28 Wing AM. Disorders of movement. In: Smyth MM, Wing AM, eds. The Psychology of Human Movement. London : Academic, 1984.

29 Mizrahi EM, Angel RW. Impairment of voluntary movement by spasticity. Ann Neurol 1979;5:594-5. 
30 Corcos DM, Gottlieb GL, Penn RD, Mykehurst B, Agarwal GC. Movement deficits caused by hyperexcitable stretch
reflexes in spastic humans. Brain 1986;109:1043-58.

31 Sahrmann SA, Norton BJ. The relationship of voluntary movement to spasticity in the upper motor neuron syndrome. Ann Neurol 1977;2:460-5.

32 Anderson $M$, Lough S. A psychological framework for neuro-rehabilitation. Physiotherapy Practice 1986;2: 74-82.

\section{Footnotes}

It would be more accurate to describe the shoulder movement as involving anatomical abduction/adduction. However, since the movement was constrained to a single plane by the arm support there is no risk of confusion.

We thank David Marsh for suggesting this transformation and Ian Nimmo-Smith for assistance with the statistical analyses.

The analyses were also carried out with all data included in the analysis. As it turned out, with the exception of the control subject, the estimates of assymptote and slope were very similar which suggests that the precaution of excluding the first session data was unnecessary.
Dechambre's description of lacunes, 1838 Miller Fisher's classic paper was based on $114(11 \%)$ cases in an unselected series of 1,042 autopsies. ${ }^{1} \mathrm{He}$ defined them as ischaemic infarcts of restricted size in the deeper parts of the brain and traced their description to Durand-Fardel's case $\mathbf{7 8}$ in a treatise on softening of the brain: ${ }^{2}$

"The striatum on each side showed a certain number of small lacunes with no associated alteration of colou or consistency from whose surface there extended a fine meshwork containing very small vessels."

Elsewhere in the monograph he recognised etat criblé. More recently GC Roman ${ }^{3}$ has drawn attention to the work of Amédée Dechambre (1812-1886) who studied in Paris, graduated from Strasbourg and dedicated his career to journalism, founding the Gazette Hebdomadaire de Médecine et de Chirugie and published a Dictionnaire Encyclopédique des Sciences Médicales in 100 volumes. The May 19 issue ${ }^{4}$ of Gazette Médicale de Paris includes his report; Case 9 was a patient studied pathologically after an initial recovery from hemiplegia: "A number of small lacunes, of variable size and form, more or less filled with a milky fluid ... resulting from liquefaction and partial reabsorption in the centre of the softening. According to the degree of hardening and reabsorption of the liquified pulp these lacunes appear empty or stay more or less filled . . . It is, no doubt, with small foci of partial softening, that these round cavities without membranes should be correlated."

Dechambre thus beat Durand-Fardel by some 5 years! JMS PEARCE

1 Fisher CM, Lacunes: Small deep cerebral infarcts. Neurology, Minneap 1965;15:774-84.

Durand-Fardel $M$, Traité du ramollissement du cerveau. Baillière. Paris 1843.

3 Roman GC. The original description of lacunes. Neurology 1986;36:85.

4 Dechambre A. Mémoire sur la curabilité du ramollissement cérébral. Gazette Médicale, Paris 1838;6:305-14. 